\title{
UNIVERSAL MILITARY SERVICE IN PEACE TIME
}

\author{
REPORT OF A SUBCOMMITTEE OF THE WAR POLICY COMMITTEE ${ }^{1}$ \\ OF THE \\ AMERICAN MATHEMATICAL SOCIETY AND THE MATHEMATICAL \\ ASSOCIATION OF AMERICA
}

Foreword (prepared by Professor M. H. Stone, Chairman of the War Policy Committee): The War Policy Committee of the American Mathematical Society and the Mathematical Association of America was formed to study the many questions of professional and scientific policy arising out of the war. No subject has been of greater interest or more vital concern to the Committee than the relations between scientific effectiveness on the one hand and the military requirements of the nation on the other. A most important aspect of this subject is treated in the report on Universal Military Service in Peace Time which is now made public. This report, prepared some time ago by a special subcommittee, is directed in the main at points upon which mathematicians as such are particularly qualified to express informed opinions. Whatever view may ultimately prevail concerning universal military training in peace time-and it should be emphasized that there are many citizens, mathematicians included, who doubt the wisdom of introducing such a peace-time military program-it is clearly of the first importance that no program deleterious to the scientific and technological vigor of the nation should be adopted. The report deals frankly and in detail with this vital segment of the problem now before Congress. In offering the recommendations of the report as a professional contribution to the current discussion, the War Policy Committee hopes to render a modest public service strictly within the natural sphere of its activity.

1. Introduction. In the Congress of the United States, bills are under consideration (S. 188 and H.R. 515, companion bills) which would prescribe a year of military service in peace time for all young men of suitable physical qualifications. These bills present the nation with a proposal for a fundamental new departure in our national life and it is appropriate that the widest discussion should occur concerning all sides of the situation which would result. It is natural that the greater part of the arguments pro or con about S. 188 in the public press should deal with military, internal political, and international

' Prepared, in July, by a subcommittee consisting of Professor W. L. Hart, Chairman, Saunders MacLane, and C. B. Morrey, and approved by the War Policy Committee and the Council of the American Mathematical Society. 
aspects of the matter. Various spokesmen of the general field of education, particularly at the college level, as well as of specific fields of learning have likewise discussed the measure under consideration. It is the main purpose of this report to state opinions concerning the impact of compulsory military service in peace time on those phases of our national life which are of primary significance to mathematicians and which lie in areas where we may speak with special authority. In carrying out this aim, it is natural that at times we shall phrase remarks from a general educational viewpoint not primarily associated with the field of mathematics. A summary of the opinions advanced in the report is to be found in Section 11.

2. Orientation of the report. In the discussion of any measure like S. 188, we may conceive of a division of interest between two major questions. First, one may ask, "Should the United States have universal military service in peace time?" Second, "If Congress is to pass such an act, what provisions should it contain in order that the greatest possible good should be obtained for the nation as a whole and for the young men who will perform the service?" We realize that these questions are considerably interrelated but, for our purposes, we shall act as if they are relatively independent. It is probable that the decision on the first question should and will be reached mainly on the basis of significant national and international considerations of a social, economic, political, and military nature. In this connection it is likely that only small weight will be given to those points where our opinions as mathematicians or educators would be of any special importance as compared to those ideas we may express individually as mere citizens. Hence we have decided that, in regard to the first question and the most intimately connected phases of the second question, we shall make only a single statement.

We believe that a decision about introducing universal military service in peace time should be reached only after an investigation by a carefully selected commission, preferably appointed by the President of the United States. We recommend that this commission should include not only representatives of the armed forces but also individuals from all other important sections of our population, with a strong representation from the fields of industry, science, and technology which have been of such great importance during the present war. This commission should have the wide objective of considering what combination of universal military service, scientific development work on weapons of war, and associated industrial and educational measures would be best adapted to insure the safety of the nation. 
The balance of this report will be concerned with matters particularly germane to a discussion of the second of the two major questions which we have mentioned, although we have no intention of considering all its aspects. Our remarks will be phrased under the explicit assumption that universal military service in peace time will be adopted. However, this viewpoint is not to be taken as evidence that we desire or expect a bill such as S. 188 to become law.

For future reference, we note that the present bill S. 188 includes the following features.

2.1. The bill omits specification of all subsidiary values as justification for military training and is based only on reasons relating to national security and the prevention of dissipation of training resources and experience.

2.2. The bill contains provision for a period of four years (ages 18 to 22) in which the individual may select the year for military training. A high school graduate with his parents' consent may volunteer to start his year of training while he is still 17 years of age.

2.3. The year of training will be used by the Army and Navy as a basis for selecting non-commissioned and commissioned officers.

3. Background relating to the present war. The importance of technical developments of new weapons and tactics during the military operations of the last few years has emphatically shown that science has made a fundamental contribution to the military power of the nation. More particularly, the abstract science of mathematics has been put to effective application in a surprising number of fields, including even the extensive use of mathematicians in operational analysis work overseas. These facts are important in the formulation of an intelligent long term policy for maintaining the nation's military strength. It can safely be said that the military potential of a country does not depend solely upon the size and character of its armed forces. This potential also depends largely upon the technical and industrial talent available and upon the vigor, ability, and training of its scientific and technical experts.

Long range military planning, therefore, requires that able young men be encouraged both in preparing themselves in basic scientific and mathematical knowledge and in acquainting themselves with the ways in which this knowledge can be put to use in time of war or national emergency.

With the preceding viewpoint in mind, we deeply regret to note that the manpower policies of the United States during the war have not been well formulated with respect to the utilization of men 
trained in science and technology or potentially able to assimilate such training. Draft deferments for the purpose of obtaining certain varieties of technical training have been at times difficult and often impossible to obtain. Some valuable technical men have been wasted in non-technical activities and others would have been wasted had it not been for the energetic efforts of representatives of science and technology in prodding reluctant or unenthusiastic government bureaus into action. During the war the United States has followed a sadly shortsighted and unintelligent policy with regard to science and technology by not providing for appropriate annual increments of undergraduate men to be trained in those fields. There are facts at hand which indicate that England and probably Russia have not made a similar error during the war. We agree strongly with the many opinions which have recently been expressed concerning the necessity for prompt resumption of training for the scientific professions, even before the end of the war with Japan. We believe that any additional delay in provisions for such training may have fatal effects not only on national health and the technological side of our economy but, also, on our means for future national defense. These remarks are well justified by the established facts about the present and potential shortages of physicians, dentists, Ph.D.'s in the various fields of the physical sciences, and technologists. The preceding background leads us to the following conclusion.

We consider it very important that universal military service in peace time should not be planned in such a way as to interfere with efforts, first, to eliminate as quickly as possible the present shortage of scientists and technologists and, second, to provide for a continuous generous supply of such essential categories of trained citizens in the future.

4. An attitude about exemptions from military service. It has been the traditional American viewpoint that all men should be treated as nearly alike as possible in fundamental respects whenever a call for universal military service is issued by our Government. It could be argued that this was a major cause for some of the shortsighted manpower policies of the present war period which have been referred to previously. However, we believe that it would have been possible for Selective Service to have been administered during the war without violating the specified tradition and, also, without introducing various major evils. This democratic viewpoint is so deeply seated that, regardless of whatever arguments might be presented against it, neither the general public nor the affected young men could be 
expected to give friendly support to measures for creating numerous exempt classes of the population in case universal military service in peace time should be adopted. Realistically, we appreciate that any request for the exemption of mathematicians or physical scientists, for instance, could be expected to induce requests for the exemption of social scientists, and scholars in almost all other fields of learning, as well as representatives designated by innumerable pressure groups outside the field of education. The result of such requests for exemptions would undoubtedly be the creation of an ironclad policy of no exemptions. The requests might even develop an unsympathetic attitude among the directors of military service with respect to rational plans for differentiation of training, which we propose to emphasize in place of exemptions.

We shall proceed, then, with the explicit premise that it would be undesirable to suggest the exemption of men with special mathematical talent and that each man, regardless of his abilities, will have to spend one year of his life in military service.

5. A liberal interpretation of the words "military service." The present rate of increase in the military uses of science and technology convinces one that success in any future war will be dependent on continued progress in science and on the existence of a large reservoir of trained technologists. Thus it is essential that any program for universal military service should be consistent with associated plans for the development of our scientific and technological potential. It follows that the final program should not be organized with the narrow objectives of merely disciplining masses of men and preparing them for handling existing weapons of war. Hence, the term "military service" should be interpreted in a liberal fashion.

"Military service" should include not only the usual routine service in the Armed Forces but, also, various other highly technical forms of training which are just as essential for enhancing the military strength of the nation. These types of service should be made available for properly qualified young men under some studied system for differentiation of training in accordance with ability. In particular, the system should provide appropriate advanced types of service in the case of the small but important group having special aptitude for and training in mathematics, the physical sciences, or technology.

6. Candidates for the most highly technical military service. During the present war, under Selective Service the Armed Forces have made intelligent efforts to place the inductees into various enlisted classifications in accordance with the abilities shown by the men in 
civilian life and in various tests given by the Armed Forces. Also, similar efforts have been made to locate men with appropriate backgrounds as candidates for commissioned ranks in various branches of the Armed Forces. It should be anticipated that these commendable practices in the direction of differentiated training would continue under universal military service in peace time. The Committee then directs the main force of its recommendation for differentiated training at the cases of the exceptionally superior young men who, let us say, have the requisite mathematical and scientific aptitude and inclination to become Ph.D.'s in mathematics or a physical science, or to advance to the highest levels of attainment in an engineering field. Under the reasonable hypothesis that less than one third of the men in our population with such potentialities finally pursue careers in the indicated fields, we are led to estimate the number of men of this sort available in any annual age group at about 3000 men. If we should attempt to sift them out of the enormous annual group of high school graduates by any existing devices for the prediction of mathematical or scientific aptitude, the percentage of error in diagnosis would be very high. It is likely that we would have to earmark about 20,000 boys annually in order to be reasonably certain that the final group would include $90 \%$ of the 3,000 boys whom we have mentioned. Such an attempt at selection of 20,000 boys would entail severe difficulties in the field of educational measurements and also many later complications if the members of the earmarked group were to be given individual attention during the next four to seven years. Our final plan will indicate a procedure for obtaining such candidates which appears more simple than an attempt to earmark them at an early age. At present we offer merely the following conclusion. Among the boys who graduate from high school in any year there is a group of about 20,000 with such high mathematical and scientific aptitude that they deserve special consideration under any plan for universal military service. This group will hereafter be referred to as the select technical group.

7. Advantages of deferment of military service for the select group. It is likely that any boy in the group would graduate from high school by the time he is 18 . Regardless of considerations related to military service, the rarity of the aptitudes present in the group makes it desirable that each member should be shielded from unnatural influences which might lead him away from the fields of science and technology where his abilities would be so valuable to the nation. We believe that he should be encouraged to carry out any latent 
inclination to enter upon scientific or technical training. Immediately after graduation from high school, an interruption of a full year in the educational process might eliminate or dim his embryonic urge to scientific study. The interruption would also cause an undesirable break in the important preliminary stages of progress in mathematics and science. Moreover, a year of military service at age 17 or 18 might expose the boy to certain military, social, or industrial activities which, although appealing to a youth, could lead him after a few years to an undesirably low terminal point outside of advanced science or technology, with a corresponding loss to the nation.

If our attention is now fastened primarily on differentiated training at a high level under military service, we can likewise argue that a delay beyond age 18 in this service may be desirable for a boy in the select group. When he graduates from high school, he will not yet possess the requisite mathematical and scientific background to be eligible for or to obtain maximum good from many of the high grade types of differentiated service which can be made available. Before he receives college training, his possibilities might be merely those of an exceptionally intelligent young man with latent scientific abilities and interests but no particularly useful background knowledge. He might even gain a permanently wrong orientation with respect to various aspects of military service where he should eventually become most useful to the nation in case of war.

The preceding remarks lead us to advocate the following flexible provision, similar to Item 2.2 , in any final regulations governing universal military service in peace time.

The directors of the program should have the power to approve a request for deferment of the year of service for any young man when this is deemed best for the interest of the nation. In particular, continued efficient progress with high achievement in the study of mathematics, a physical science, or technology, even through the stage of a Ph.D. degree, should be considered sufficient cause for such deferment.

Conceivable complications in the administration of the rules for deferment should not be considered a deterrent to the adoption of the preceding recommendation. It should be possible to develop a smooth routine for such a process in peace time which would be superior to the method employed with respect to draft deferments of scientists and scientific students during the war. In this connection it is pertinent to observe that a proposal for special treatment immediately under Selective Service for a select group of 20,000 was presented to Congress recently. 
8. Suggestions concerning highly differentiated service. We proceed under the assumption that the deferment recommendation of Section 7 could be adopted. Then, we propose the following rough outlines of a plan for implementing the suggestions about differentiated service.

8.1. A board should be created to canvass the possibilities for in service training on intermediate and high technical levels for properly qualified applicants and to supervise plans for instituting such training. This board should involve civilian representatives of the fields of mathematics, the physical sciences, and engineering, together with representatives of the armed forces.

8.2. The search for training locations should cover the various laboratories, research divisions, arsenals, and other technical activities of the Army and Navy. Also, the search should extend into associated private industries and related curricula and research in universities. As a mere sample of possibilities we mention the following types of training which might be given to properly selected groups each year.

8.21. An advanced course in meteorology for the future use of the Army or Navy, along the lines of the curriculum presented at five major universities in the United States during the early years of the war, and associated field experience.

8.22. In service training at the Ballistic Research Laboratory of the Army Ordnance Department at the Aberdeen Proving Ground.

8.23. In service training in the artillery fire control division at an ordnance plant.

8.24. In service training at a laboratory of the Signal Corps, or at an aeronautical research laboratory of either the Army, the Navy, private industry, or a university.

8.25. Study of the mathematical and operation phases of cryptanalysis in the intelligence division of the Army or Navy.

8.3. For each of the training possibilities, the Board should decide upon appropriate academic prerequisites to be demanded of any man who is to qualify for the opportunity. These prerequisites should probably be much more extensive than for any similar training during the war, because in peace time interested men would have ample opportunity to obtain the necessary background. A pamphlet should then be published listing the available varieties of technical training which might be taken as "military service" so that interested boys, even early in their high school life, could begin to orient their school work with respect to the future opportunities in military service. The pamphlet should urge boys of proper aptitudes to defer their entrance to military service until they gain the prerequisites for the type or types of service which appeal to them. 
8.4. If administratively possible, assignments to any one of the most exacting and desirable varieties of training should be made on the basis of applications asserting definite interest in the field involved, as well as possession of the necessary prerequisites.

8.5. In addition to the technical training experience mentioned previously, an appropriate amount of routine "boot" training should be given either simultaneously with the technical work or in a separate period of time during the year of service.

8.6. The directing Board should examine the possibility of granting commissions in the Reserve Corps of the Army or Navy for satisfactory completion of certain types of technical training which would be available to the most highly qualified young men during their year of service. Acceptance by a young man of the opportunity of such training should not commit him to accepting such later commission as might be offered in this connection.

9. Civilian educational by-products of universal military service. If the interesting nature of the various technical types of differentiated military service, at low or intermediate as well as at high levels, and the corresponding academic prerequisites are properly advertised, strong repercussions might occur in the field of secondary education. It is probable that boys of ability and their parents would then demand maximum mathematical and scientific opportunities in the secondary curriculum for students of proper ability. Also, regardless of the possibility of differentiated training, it is our belief that a requirement of a year of military service, with the attendant delay in the study of the professions, would place an added demand for educational efficiency on both the high schools and colleges. The knowledge resulting from a brief exposure to substantial secondary mathematics or science is easily forgotten. On the other hand, a long exposure to these fields gives the student a body of content which, even though it should remain dormant during a year of military service, would be effective in the next year after a brief review.

Hence, if universal military service is adopted, added efforts should be made in the secondary field to expose the better students to as much substantial mathematics and physical science as possible.

10. Educational responsibilities of the Armed Forces resulting from universal military service. Even without the delay which would be caused by military service, the time for completing professional training encroaches on the age of greatest productivity and ingenuity as well as on the normal age for assumption of family responsibilities. 
Hence, under universal military service, the Armed Forces will be presented with a challenge to compensate as much as possible for the year of delay which would be introduced. It is obvious that the handicaps suffered by a young man due to an interruption of a year in his formal education would be considerably lessened if he should systematically carry on correspondence study during the year.

If universal military service is adopted, the Armed Forces should offer to the men in training the fullest cooperation and encouragement in the extension of their formal education by means of correspondence courses. At the college level, we recommend that this be done by paying the registration fees for men who take and diligently pursue courses offered by regular college correspondence departments, rather than through such an agency as the present Armed Forces Institute.

11. Summary. In the development of this report we have emphasized the following points and recommendations.

11.1. A joint civilian and military commission should be appointed by the President of the United States to study the problem of universal military service in peace time before final action is taken on the matter.

11.2. An expression of opinions by the American Mathematical Society and the Mathematical Association of America should be focused on constructive suggestions about the administration of universal military service if it should be adopted and about the solution of resulting educational problems.

11.3. No outright exemptions from universal military service should be requested.

11.4. The required military service should be highly differentiated in accordance with the aptitudes and training of the young men involved, with emphasis on exceptional differentiation for those few with the greatest technical abilities.

11.5. A system for deferring the year of military service should be instituted so that gifted young men might prepare themselves for advanced varieties of differentiated service before entering the Armed Forces.

11.6. The possibilities for technical varieties of differentiated service should be canvassed by a joint civilian and military board. The resulting training programs with the corresponding academic prerequisites should be well advertised among high school boys, their parents, and the teachers and administrators in the secondary field. 
11.7. If universal military service is adopted, the field of secondary education will have the added responsibility of increasing the efficiency and quantity of instruction given in mathematics and physical science to the students of better than average ability.

11.8. The Armed Forces should encourage young men to continue their education during military service by taking correspondence work through regular school channels, and the Armed Forces should pay the costs of such study if a man carries it through diligently.

\section{PREDOCTORAL FELLOWSHIPS IN THE NATURAL SCIENCES}

The National Research Council announces that it is now ready to receive nominations and applications for the predoctoral fellowships in the natural (that is mathematical, physical, and biological) sciences which it is administering under a grant from the Rockefeller Foundation. These fellowships are intended to assist young men and women, whose graduate study has been prevented or interrupted by the war, to complete their work for the doctorate. It is hoped that these fellowships will do much to accelerate the recovery of the scientific vigor and competence of the country which is so seriously threatened by the loss of almost two graduate school generations of scientifically trained men and women.

This program will be administered by a Committee on Predoctoral Fellowships of the National Research Council whose members are Henry A. Barton, Charles W. Bray, Detlev W. Bronk, Luther P. Eisenhart, Ross G. Harrison (Chairman-National Research Council, ex officio), W. A. Noyes, Jr., and John T. Tate, chairman; Enid Hannaford, secretary.

The annual stipend will be $\$ 1200$ for single persons and $\$ 1800$ for married men. In general it is expected that each recipient will spend at least eleven months per year on academic work. An additional allowance up to $\$ 500$ per year will be made for tuition fees. Fellowships granted to individuals who are eligible for educational support from the "G.I. Bill of Rights" will be at such stipends as to bring the total income from these two sources to that which would be received at the above rates.

Each fellow, before entering on his graduate studies, will submit for review by the Committee on Predoctoral Fellowships a schedule, 